\section{Is Screening for Hepatitis Necessary in Diagnostic Evaluation of Rheumatoid Arthritis in South Korea?}

\section{To the Editor:}

We read with interest the article by Guennoc, et $a l^{1}$ reporting that seroprevalences of hepatitis B (HBV) and hepatitis C (HCV) in patients with recent-onset polyarthritis who were suspected of rheumatoid arthritis (RA), were very low and were not different compared to the general population. Thus, they proposed that serological testing for HBV and HCV is unnecessary in routine diagnostic evaluation for these patients. Currently in our institution, simultaneous serological testing for $\mathrm{HBV}$ and $\mathrm{HCV}$ and even hepatitis A (HAV) is performed on patients suspected of RA as part of a routine diagnostic evaluation. We performed this study to also check the usefulness of such routine diagnostic evaluation of hepatitis.

We investigated the hepatitis test results in patients who visited The Hospital for Rheumatic Diseases and were diagnosed with RA during an 8-year period, from January 2001 to December 2008. Hepatitis B surface antigen (HBsAg)-positive was found in $3.5 \%$ of patients (140/3946), while anti-HCV-positive was found in $1.1 \%$ of patients (38/3448). The HAV-IgM test used for the diagnosis of HAV was positive in $3.77 \%$ of patients (140/2594). Looking at the yearly trend of positive rates, there was a decreasing trend for $\mathrm{HBsAg}$, but no large change was seen for anti-HCV (Figure 1). For HAV, yearly positive rates showed large fluctuations and there was an abrupt increase in 2008 (Figure 2).

Korea had high HBsAg-positive rates of $7 \%$ to $8 \%$ in the 1980 s, but the figures fell to $4.4 \%$ in men and $3.0 \%$ in women in 2005 through continuous vaccination programs ${ }^{2}$. These figures did not differ much from the results we obtained from patients with RA. However, the positive rate was higher than the result reported by Guennoc, et al $(0.86 \%)$. The anti-HCV-positive rate was known to be around $1 \%$ in Korean adults ${ }^{2}$, and this was similar to our result. However, the positive rate was lower than the anti-HCV result reported by them.

As Korea achieved rapid economic development since the mid-1970s, changes appeared in the positive rate of the HAV antibody. According to data from the end of the 1970 s, $100 \%$ of the domestic population above age 15 had the antibody, but by the end of the 1990s there was a distinct decrease. In people under age 20 years, the positive rate was a very low $20 \%$. The rate was $40 \%-60 \%$ for ages $20-30$, and $80 \%-90 \%$ for those

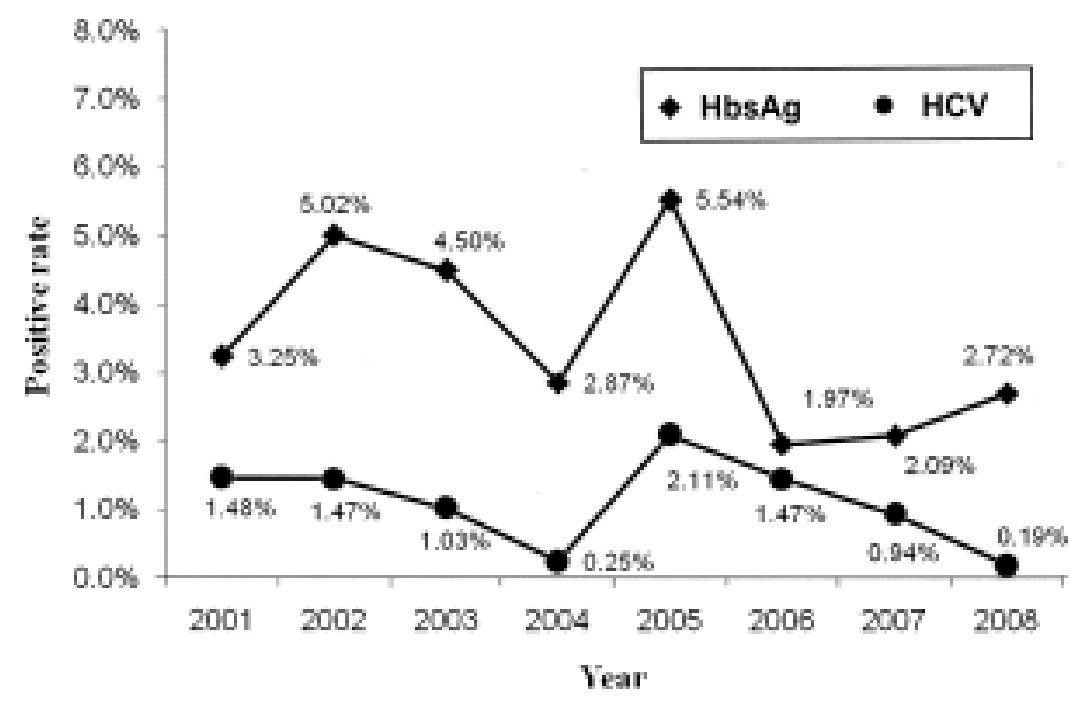

Figure 1. Annual positive rates for serum hepatitis B surface antigen (HbsAg) and anti-hepatitis C (HCV) in patients with rheumatoid arthritis $(n=3946$ for HbsAg, $n=3448$ for anti-HCV).

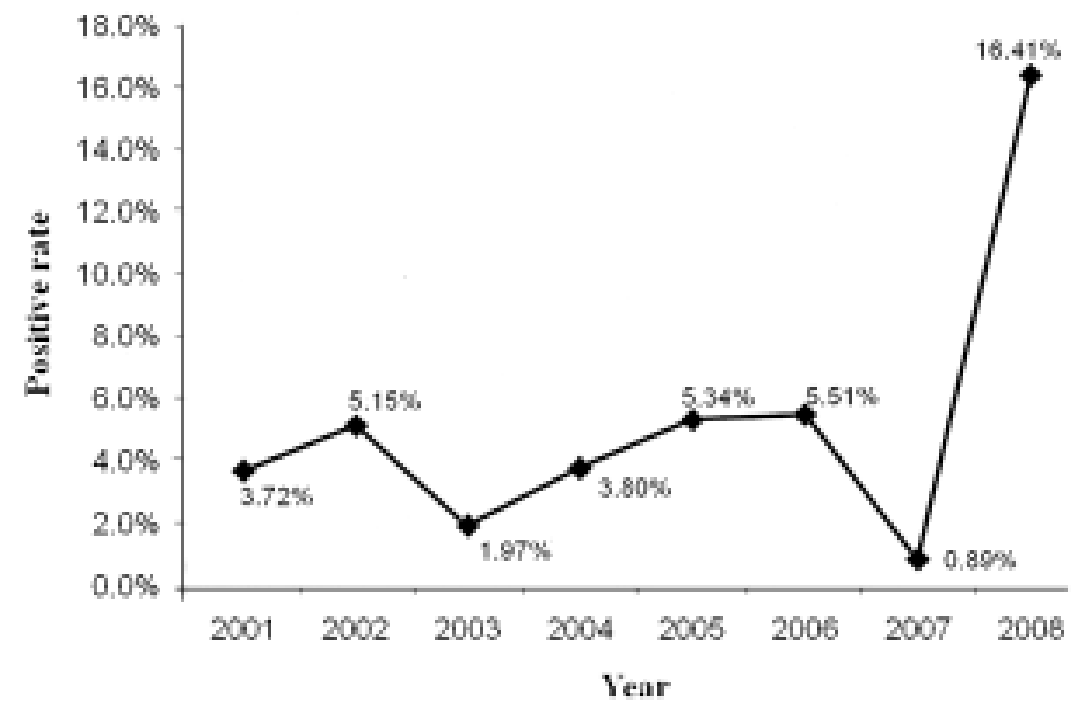

Figure 2. Annual positive rates for serum anti-HAV-IgM in patients with rheumatoid arthritis $(\mathrm{n}=2594)$. 
older than $30^{3}$. According to Jung, et al, positive rates of the antibody were $1.8 \%$ for those under 24 years, $14.7 \%$ for ages $25-29,41.8 \%$ for ages $30-34,75.5 \%$ for ages $35-39$, and $93.7 \%$ for ages above 40 years. These rates indicated the high possibility of HAV infection in the age group between 20 and 40 years ${ }^{4}$. In our study of patients with RA, there was a suspicious outbreak of HAV infection in 2008, and this was confirmed by data from the Korean Center for Disease Control ${ }^{2}$.

Although Guennoc and colleagues proposed that routine screening for $\mathrm{HBV}$ and $\mathrm{HCV}$ is not needed in their region, we believe that the HBV test should be included in the diagnosis of RA since there is still a high prevalence of HBV hepatitis in Korea. However, we think that the test for HCV could be discarded. Also, since the HAV is the most common type of acute hepatitis, we believe that the test for HAV must be included.

DUCK-AN KIM, MD; THINK-YOU KIM, MD, Department of Early Arthritis/Laboratory Medicine, The Hospital for Rheumatic Diseases, Hanyang University Medical Center, 17 Haengdang-dong Seongdong-gu, Seoul 133-792, South Korea. Address correspondence to Dr. T-Y. Kim; E-mail: tykim@hanyang.ac.kr

\section{REFERENCES}

1. Guennoc X, Narbonne V, Jousse-Joulin S, Devauchelle-Pensec V, Dougados M, Daurès JP, et al. Is screening for hepatitis B and hepatitis $\mathrm{C}$ useful in patients with recent-onset polyarthritis? The ESPOIR cohort study. J Rheumatol 2009;36:1407-13.

2. The Korea Centers for Disease Control and Prevention. [Internet. Accessed November 13, 2009.] Available from: http://www.cdc.go.kr/.

3. Lee EJ, Kwon SY, Seo TH, Yun HS, Cho HS, Kim BK, et al. Clinical features of acute hepatitis A in recent two years. Korean J Gastroenterol 2008;52:298-303.

4. Jung SI, Lee CS, Park KH, Kim ES, Kim YJ, Kim GS, et al. Sero-epidemiology of hepatitis A virus infection among healthcare workers in Korean hospitals. J Hosp Infect 2009;72:251-7.

J Rheumatol 2010;37:3; doi:10.3899/jrheum.090886 